\title{
The effect of short pregnancy interval on perinatal outcomes in Turkey: A retrospective study
}

\author{
Nevsen Saral ${ }^{1}$, Seval Cambaz Ulas²
}

\begin{abstract}
Objective: The aim of the study was to determine the effect of short pregnancy interval on perinatal outcomes.

Methods: The research was a retrospective study. The material consisted of birth records of a state hospital for the last three years in Manisa in the western region of Turkey (2015-2017) (n:8961). The research population included women whose gestational interval was stwo years and the gestational week was over 22 weeks (n:2089). Perinatal outcomes were assessed through preterm birth, stillbirth, and low birth weight.

Results: The mean age of women who are in the research group is $26.7 \pm 5.32$. According to the perinatal results of women with a pregnancy interval of two years and shorter; $8.2 \%$ of women had birth before 37 weeks and $0.3 \%$ resulted in stillbirth. It was determined that $4.8 \%$ of infants were born with low birth weight. There was no difference between the short pregnancy interval and stillbirth or preterm birth. However, a significant difference was found between the low birth weight and short pregnancy interval. $(p>0.05)$.

Conclusions: Pregnancy interval does not affect preterm birth and stillbirth from perinatal outcomes, but has a significant effect on the birth weight of the newborn.
\end{abstract}

KEYWORDS: Low birth weight, Pregnancy interval, Preterm birth, Stillbirth.

doi: https://doi.org/10.12669/pjms.35.5.837

How to cite this:

Saral N, Ulas SC. The effect of short pregnancy interval on perinatal outcomes in Turkey: A retrospective study. Pak J Med Sci. 2019;35(5):1243-1247. doi: https://doi.org/10.12669/pjms.35.5.837

This is an Open Access article distributed under the terms of the Creative Commons Attribution License (http://creativecommons.org/licenses/by/3.0), which permits unrestricted use, distribution, and reproduction in any medium, provided the original work is properly cited.

\section{INTRODUCTION}

1. Nevsen Saral,

Department of Midwife,

Manisa City Hospital,

Manisa, Turkey.

2. Seval Cambaz Ulas,

Department of Midwifery,

Faculty of Health Sciences,

Manisa Celal Bayar University,

Manisa, Turkey.

Correspondence:

Seval Cambaz Ulas,

Department of Midwifery,

Faculty of Health Sciences,

Manisa Celal Bayar University,

Manisa, Turkey.

E-mail: seval.cambaz@hotmail.com

* Received for Publication:

* $1^{\text {st }}$ Revision Received:

* $2^{\text {nd }}$ Revision Received:

* Final Revision Accepted: *

Pak J Med Sci September - October 2019
April 5, 2019

April 18, 2019

June 18, 2019

June 19, 2019
The World Health Organization states that the pregnancy interval is time between the delivery date of the preceding live birth and conception date of the index pregnancy in women who have had more than one birth. ${ }^{1}$ The risk of complications increases in pregnancies that occur less than two years and they are considered to be highrisk pregnancies. High-risk pregnancies are of particular importance because of increased risk of illness or death before, during, and after birth. ${ }^{2}$ Nonoptimal pregnancy interval that is either too short or too long contributes to adverse maternal and perinatal outcomes in both low and high income countries. ${ }^{3}$ The other studies conducted on this issue support the results of this research. ${ }^{4-6}$ Especially short pregnancy interval of less than 18 months have been associated with several bad fetal 
and neonatal outcomes such as pre-term birth, low birth weight (LBW), stillbirth, and newborn/infant mortality. ${ }^{5}$

Regardless of the gestational age, babies under 2500 grams of birth weight are considered "low birth weight" ${ }^{7}$ The short period of time between the two pregnancies is reported to cause inadequacy of the renovation of the mother nutrient depot and consequently cause the baby to born with low birth weight. ${ }^{8}$ There is $22.8 \%$ chance of low birth weight in short pregnancy interval as compared normal pregnancy interval (12.1\%). ${ }^{9}$

Short pregnancy interval is also a risk factor for preterm birth. ${ }^{10}$ Short pregnancy interval can cause preterm birth by increasing the risk of cervical insufficiency and infection. ${ }^{11}$ Preterm birth is prevalent up to $5 \%$ to $7 \%$ of among live birth in urbanized countries. ${ }^{12}$ It has been reported that the rate of preterm birth $<37$ weeks was higher in women with short pregnancy interval $<12$ $(20.1 \%)$ compared with normal pregnancy interval $(7.7 \%){ }^{13}$

The risk of neonatal death due to short pregnancy interval is high. The perinatal mortality was increased by 3-4 times in patients with an interval of fewer than 12 months between pregnancies, while infant mortality was increased by 2 times. ${ }^{11}$

Different cut-off points have been considered for nonoptimal pregnancy interval in the literature.
The optimal pregnancy interval (24 months) was considered as the cut-off point in this study. The aim of this study was to determine the effect of short pregnancy intervals on perinatal outcomes.

\section{METHODS}

The research is a retrospective study. The research used the birth records of a state hospital in Manisa in the western region of Turkey for the last three years (2015-2017) (N:8961). All pregnant women who met the criteria for including to the research in the years of 2015 - 2017 (n: 2089) were included. The criteria for including to the research are determined as gestational interval of the pregnant women should be $\leq 2$ years and the gestational week of pregnant women should be over 22 weeks.

The data of the study were collected using a data collection form consisting of 21 questions. The data collection form was created by evaluating the data where the records that can be obtained through the system are complete. We evaluated three adverse perinatal outcomes: low birth weight (less than $2500 \mathrm{~g}$ ), preterm birth (birth at less than 37 weeks' gestation), and stillbirth. Number, percentage distribution and Chi-square test were used for the evaluation of research data. The study received approval from Medicine Health Sciences Ethics Committee of Manisa Celal Bayar University Faculty and state hospital.

Table-I: Descriptive characteristics of women by pregnancy interval.

\begin{tabular}{|c|c|c|c|c|c|c|c|}
\hline \multirow[t]{3}{*}{ Characteristic } & & \multicolumn{6}{|c|}{ Pregnancy Interval } \\
\hline & & \multicolumn{2}{|c|}{2 years } & \multicolumn{2}{|c|}{$<2$ years } & \multicolumn{2}{|c|}{ Total $^{* *}$} \\
\hline & & Number & $\%$ & Number & $\%$ & Number & $\%$ \\
\hline \multicolumn{8}{|l|}{ Age } \\
\hline \multirow[t]{3}{*}{ Mean \pm Sd: (26.7 \pm 5.32$)$ Min:16 Max:45 } & $16-25$ & 420 & 42.8 & 562 & 57.2 & 982 & 47.0 \\
\hline & $26-35$ & 452 & 47.4 & 501 & 57.6 & 953 & 45.6 \\
\hline & $36-45$ & 68 & 44.2 & 86 & 55.8 & 154 & 7.4 \\
\hline \multirow[t]{4}{*}{ Pregnancy number } & 2 & 435 & 46.9 & 493 & 53.1 & 928 & 44.4 \\
\hline & 3 & 262 & 44.6 & 325 & 55.4 & 587 & 28.1 \\
\hline & 4 & 132 & 43.9 & 169 & 56.1 & 301 & 14.4 \\
\hline & 5 and above & 111 & 40.7 & 162 & 59.3 & 273 & 13.1 \\
\hline \multirow[t]{3}{*}{ Number of live births } & 1 & 34 & 15.3 & 188 & 84.7 & 222 & 10.6 \\
\hline & 2 & 528 & 47.7 & 578 & 52.3 & 1106 & 52.9 \\
\hline & 3 and above & 378 & 49.7 & 383 & 50.3 & 761 & 36.5 \\
\hline \multirow[t]{2}{*}{ The presence of chronic disease } & Yes & 30 & 39.0 & 47 & 61.0 & 77 & 3.7 \\
\hline & No & 910 & 45.2 & 1102 & 54.8 & 2012 & 96.3 \\
\hline \multirow[t]{2}{*}{ Smoking } & Yes & 91 & 44.4 & 114 & 55.6 & 205 & 9.8 \\
\hline & No & 849 & 45.1 & 1035 & 54.9 & 1884 & 90.2 \\
\hline Total & & 940 & 45.0 & 1140 & 55.0 & 2089 & 100.0 \\
\hline
\end{tabular}

** Column percentage is given. 


\section{RESULTS}

The time between two pregnancies in $55.0 \%$ of women in the research is shorter than 2 years. The mean age of women is $26.7 \pm 5.32$. The number of pregnancies for $44.4 \%$ of women was 2 , and $52.9 \%$ had 2 live births. It was determined that $3.7 \%$ of the women in the research group had a chronic disease, and $9.8 \%$ were smoking (Table-I).

The previous pregnancy of approximately $84.0 \%$ of women has resulted in a birth. The gestational age of birth for $0.8 \%$ of women (according to the ultrasound) is 33 weeks and below. It was determined that $1.1 \%$ of women had a pregnancyinduced disease and $36.7 \%$ had anemia (hemoglobin value was under $11.0 \mathrm{~g} / \mathrm{dl}$ ) (Table-II).

Looking at the characteristics of infants in the research; $99.7 \%$ were born alive, $99.5 \%$ of newborns were singular, $48.6 \%$ were female. The weight of $0.7 \%$ of infants are $2000 \mathrm{~g}$ and below; $23.8 \%$ shorter than normal. The first minute of the APGAR score of $0.9 \%$ of the infant was between $0-6$, and the fifth minute APGAR score of $0.4 \%$ of the infant was determined to be between 0-6. In addition, 8.7\% of infants were determined to need intensive care (Table-III). The short gestational interval had no significant effect on preterm birth and stillbirth but it was determined to create a significant difference in terms of birth weight (Table-IV, $\mathrm{p}<0.05$ ).

\section{DISCUSSION}

The study showed that $55 \%$ of women become pregnant in less than two years. In a study of pregnancy interval results in Israel, it was reported that the pregnancy interval short than 24 months was $54.1 \%{ }^{14}$ In a prospective cohort study, $26.5 \%$ of the women included in the study had a pregnancy repeat within 18 months. ${ }^{15}$ It was found that this rate was $18.8 \%$ when the research data were reevaluated according to gestation intervals of 18 months. The research findings are consistent with the relevant literature. $84.0 \%$ of women's previous pregnancy resulted in birth. In a study where the effects of pregnancy interval were investigated, $89.5 \%$ of pregnancies resulted in birth. ${ }^{16}$

In the study, $8.2 \%$ of the births occurred before 37 weeks. It was found that the short pregnancy interval did not have a significant effect on preterm birth. The short pregnancy interval has been recognized as a risk factor for preterm birth. ${ }^{17}$ It was found that the short pregnancy interval is related with preterm birth rates according to the studies which were conducted in different countries as Tanzania and Canada. ${ }^{18,19}$ Contrary to this it was determined that short pregnancy intervals were not related with preterm birth rates in a study conducted in Pakistan which is similar to the findings of this study. ${ }^{20}$

The study also found that $0.3 \%$ of women had given stillbirth and the pregnancy interval did not have a significant effect on stillbirth. There are almost 3.2 stillbirths per 1000 births all over the world each year. The highest absolute numbers (approximately stillbirth rates are 32 per 1000) of stillbirths occur in Sub-Saharan Africa and South Asia. ${ }^{21}$ However in many high-income countries (Europe, North America and Australia vb.), for every neona-

Table-II: Pregnancy characteristics of women by pregnancy interval.

\begin{tabular}{|c|c|c|c|c|c|c|c|}
\hline \multirow[t]{3}{*}{ Characteristic } & & \multicolumn{6}{|c|}{ Pregnancy Interval } \\
\hline & & \multicolumn{2}{|c|}{2 years } & \multicolumn{2}{|c|}{$<2$ years } & \multicolumn{2}{|c|}{ Total $* * *$} \\
\hline & & Number & $\%$ & Number & $\%$ & Number & $\%$ \\
\hline \multirow{2}{*}{$\begin{array}{c}\text { The shape of the previous } \\
\text { pregnancy termination }\end{array}$} & Birth & 872 & 49.8 & 880 & 50.2 & 1752 & 83.9 \\
\hline & Abortus & 68 & 20.2 & 269 & 79.8 & 337 & 16.1 \\
\hline Gestational Age* (USG) & $23-27$ & - & - & 3 & 100.0 & 3 & 0.1 \\
\hline Mean $\pm S d(39.10 \pm 1.50)$ & $28-33$ & 4 & 28.6 & 10 & 71.4 & 14 & 0.7 \\
\hline \multirow[t]{2}{*}{ Min:23.00. Max:42.60 } & $34-39$ & 637 & 45.9 & 750 & 54.1 & 1387 & 67.4 \\
\hline & $40-42$ & 282 & 43.1 & 372 & 56.9 & 654 & 31.8 \\
\hline \multirow[t]{2}{*}{ Pregnancy-Induced Disease } & Evet & 10 & 41.7 & 14 & 58.3 & 24 & 1.1 \\
\hline & Hayir & 930 & 45.0 & 1135 & 55.0 & 2065 & 98.9 \\
\hline Hemoglobin value & $7.20-9.00$ & 51 & 44.0 & 65 & 56.0 & 116 & 5.6 \\
\hline Mean $\pm S d(11.54 \pm 1.52)$ & $9.10-11.00$ & 323 & 49.8 & 326 & 50.2 & 649 & 31.1 \\
\hline \multirow[t]{2}{*}{ Min:7.20 Max:18.90 } & $11.10-13.00$ & 451 & 44.7 & 558 & 55.3 & 1009 & 48.3 \\
\hline & 13.10 ve üzeri & 115 & 36.5 & 200 & 63.5 & 315 & 15.1 \\
\hline Total & & 940 & 45.0 & 1140 & 55.0 & 2089 & 100.0 \\
\hline
\end{tabular}

*31 people have a missing data. ${ }^{* *}$ Column percentage is given. 
Nevsen Saral et al.

Table-III: Descriptive properties of the newborn by pregnancy interval.

\begin{tabular}{|c|c|c|c|c|c|c|c|}
\hline \multirow[t]{3}{*}{ Characteristic } & & \multicolumn{6}{|c|}{ Pregnancy Interval } \\
\hline & & \multicolumn{2}{|c|}{2 years } & \multicolumn{2}{|c|}{$<2$ years } & \multicolumn{2}{|c|}{ Total $^{* *}$} \\
\hline & & Number & $\%$ & Number & $\%$ & Number & $\%$ \\
\hline \multirow[t]{2}{*}{ Number of babies } & Singular & 935 & 45.0 & 1144 & 55.0 & 2089 & 99.5 \\
\hline & Plural & 5 & 50.0 & 5 & 50.0 & 10 & 0.5 \\
\hline \multirow[t]{2}{*}{ Whether the baby is living } & Live & 942 & 45.0 & 1151 & 55.0 & 2093 & 99.7 \\
\hline & Dead & 3 & 50.0 & 3 & 50.0 & 6 & 0.3 \\
\hline \multirow[t]{2}{*}{ The gender of the baby } & Female & 420 & 41.4 & 597 & 58.6 & 1017 & 48.6 \\
\hline & Male & 525 & 48.4 & 557 & 51.6 & 1082 & 51.4 \\
\hline \multirow[t]{3}{*}{ Baby weight } & $2000 \mathrm{~g}$ and below & 7 & 35.7 & 9 & 64.3 & 16 & 0.7 \\
\hline & $2010-2500 \mathrm{~g}$ & 27 & 30.0 & 56 & 70.0 & 83 & 3.8 \\
\hline & $2510 \mathrm{~g}$ and above & 916 & 45.7 & 1084 & 54.3 & 2000 & 95.5 \\
\hline \multirow[t]{2}{*}{ Baby's length } & $47 \mathrm{~cm}$ and below & 211 & 42.4 & 296 & 57.6 & 507 & 23.8 \\
\hline & $48 \mathrm{~cm}$ and above & 729 & 45.8 & 863 & 54.2 & 1592 & 76.2 \\
\hline \multirow[t]{2}{*}{ Apgar score (1 min) } & $0-6$ & 14 & 41.2 & 20 & 58.8 & 34 & 0.9 \\
\hline & $7-10$ & 931 & 45.1 & 1134 & 54.9 & 2065 & 99.1 \\
\hline \multirow[t]{2}{*}{ Apgar score (5 min) } & $0-6$ & 8 & 61.5 & 5 & 38.5 & 13 & 0.4 \\
\hline & $7-10$ & 937 & 44.9 & 1149 & 55.1 & 2086 & 99.6 \\
\hline \multirow{2}{*}{$\begin{array}{l}\text { Baby's intensive care } \\
\text { requirement }\end{array}$} & Yes & 72 & 37.4 & 118 & 62.6 & 190 & 8.7 \\
\hline & No & 870 & 45.7 & 1033 & 54.3 & 1903 & 91.3 \\
\hline Total & 945 & 45.0 & 1154 & 55.0 & 2099 & 100.0 & \\
\hline
\end{tabular}

** The percentage of column is given.

tal death there are now approximately 1.7 stillbirth (stillbirth rates are below 5 per 1000 births). ${ }^{22}$ The stillbirth rate in Turkey is 1 per 1000 births..$^{23}$ The stillbirth rate of Turkey is on the level of developed countries. The stillbirth rate which was found in this study is lower than the rate for stillbirths of Turkey. The data for the research were acquired from the last three years' data of a single hospital, therefore it supposed that there is not a significant relationship between stillbirth and short pregnancy interval.

It was determined that $4.8 \%$ of infants were born with low birth weight and that the short gestational interval created a significant difference in terms of baby's birth weight. According to the data of the
Turkish Population Health Survey (2013); 10\% of the children whose birth weight are known are at a low birth rate. ${ }^{23} \mathrm{Zhu}$ et al determined that women with short pregnancy intervals had an increased risk of low birth weight in their babies. ${ }^{24}$ The findings of the researchs which were conducted in Egypt ${ }^{25} \operatorname{Iran}^{26}$ and Turkey ${ }^{27}$ have shown similar results. The present research findings are consistent with the literature.

\section{CONCLUSION}

In this study, where the effect of short gestational intervals on perinatal outcomes is investigated, perinatal results were evaluated in three

Table-IV: Evaluation of the effect of pregnancy interval on perinatal outcomes.

\begin{tabular}{|c|c|c|c|c|c|c|c|c|c|}
\hline \multirow[t]{3}{*}{ Characteristic } & & \multicolumn{6}{|c|}{ Pregnancy Interval } & \multicolumn{2}{|c|}{ Test value*/p } \\
\hline & & \multicolumn{2}{|c|}{2 years } & \multicolumn{2}{|c|}{$<2$ years } & \multicolumn{2}{|c|}{ Total $^{* *}$} & & \\
\hline & & Number & $\%$ & Number & $\%$ & Number & $\%$ & & \\
\hline \multirow[t]{2}{*}{ Preterm birth } & $<37$ week & 105 & 61.4 & 66 & 38.6 & 171 & 8.2 & 3.08 & 0.07 \\
\hline & $\geq 37$ week & 1044 & 54.4 & 874 & 45.6 & 1918 & 91.8 & & \\
\hline \multirow[t]{2}{*}{ Stillbirth } & Yes & 3 & 50.0 & 3 & 50.0 & 6 & 0.3 & 0.06 & 0.80 \\
\hline & No & 1146 & 55.0 & 937 & 45.0 & 2093 & 99.7 & & \\
\hline \multirow[t]{2}{*}{ Low Birth Weight (n:2099) } & below $2500 \mathrm{~g}$ & 65 & 69.1 & 29 & 30.9 & 94 & 4.5 & 7.95 & 0.00 \\
\hline & above $2500 \mathrm{~g}$ & 1084 & 54.3 & 911 & 45.7 & 1995 & 95.5 & & \\
\hline Total & & 1149 & 55.0 & 940 & 45.0 & 2089 & 100.0 & & \\
\hline
\end{tabular}

* The Pearson Chi-squared test value, ** The percentage of column is given. 
subheadings. Pregnancy interval does not affect preterm birth and stillbirth from perinatal outcomes but has a significant effect on the birth weight of the newborn. Furthermore, more than half of the women who were included to this study conceived before the optimal pregnancy interval in this study. It supposed that increasing to take proper contraceptive medicines and raising awareness of women for perinatal outcomes are important for both women and children health aspects.

Limitations of the study: The data of the research is from a single hospital for a period of three years.

Financial support: No financial support was received for the research.

Conflict of interest: There is also no conflict of interest between authors.

\section{REFERENCES}

1. DaVanzo J, Razzaque A, Rahman M, Hale L. The Effects of Birth Spacing on Infant and Child Mortality. Pregnancy Outcomes and Maternal Morbidity and Mortality in Matlab, Bangladesh. [Cited 2019 June 10]. Available from: https:// www.rand.org/content/dam/rand/pubs/working_ papers/2004/RAND_WR198.pdf

2. World Health Organization. Report of a WHO technical consultation on birth spacing. Geneva, Switzerland, 1315 June 2005. 2007 [cited 2019 June 10]. Available from: www.who.int/maternal_child_adolescent/.../birth_ spacing_cover.pdf

3. Cleland J, Conde-Agudelo A, Peterson H, Ross J, Tsui A. Contraception and health. Lancet. 2012;380:149-156. doi: 10.1016/S0140-6736(12)60609-6.

4. Wendt A, Gibbs CM, Peters S, Hogue CJ. Impact of Increasing Inter-pregnancy Interval on Maternal and Infant Health. Paediatr Perinat Epidemiol. 2012;26(Suppl. 1):239-258. doi: 10.1111/j.1365-3016.2012.01285.x.

5. Conde-Agudelo A, Rosas-Bermudez A, Kafury- Goeta AC. Birth spacing and risk of adverse perinatal outcomes - a meta-analysis. JAMA. 2006;295(15):1809-1823. doi: 10.1001/ jama.295.15.1809

6. Mignini LE, Carroli G, Betran AP, Fescina R, Cuesta $\mathrm{C}$, Campodonico $\mathrm{L}$, et al. Interpregnancy interval and perinatal outcomes across Latin America from 1990 to 2009: a large multi-country study. BJOG. 2016;123:730-737. doi: 10.1111/1471-0528.13625.

7. DaVanzo J, Hale L, Razzaque A, Rahman M. Effects of interpregnancy interval and outcome of the preceding pregnancy on pregnancy outcomes in Matlab, Bangladesh. BJOG. 2007;114:1079-1087. doi: 10.1111/j.14710528.2007.01338.x.

8. Yilmaz AE. High-risk newborn, "Newborn Health and Diseases for Midwives" (First edition), Genç RE, Ozkan H. (Eds), Anadolu Nobel Kitabevleri, Elazı̆̆ , Pakistan.2016; pp 199.

9. Zhu BP, Rolfs RT, Nangle BE, Horan JM. Effect of the interval between pregnancies on perinatal outcomes. N Engl J Med. 1999;340:8;589-594. doi: 10.1056/NEJM199902253400801

10. Van Eijsden M, Smits LJ, Van der Wal MF, Bonsel GJ. Association between short interpregnancy intervals and term birth weight: the role of folate depletion. Am J Clin Nutr. 2008;88(1):147-153. doi: 10.1093/ajcn/88.1.147
11. ACOG. Committee Opinion No. 736: Optimizing postpartum care. Obstet Gynecol. 2018;131:140-150. doi: 10.1097/ AOG.0000000000002633.

12. Beck S, Wojdyla D, Say L, Betran AP, Merialdi M, Requejo JH, et al. The worldwide incidence of preterm birth: a systematic review of maternal mortality and morbidity. Bull World Health Organ. 2010;88(1):31-38. doi: 10.2471/BLT.08.062554.

13. De Franco EA, Ehrlich S, Muglia LJ. Influence of interpregnancy interval on birth timing. Br J Obstet Gynecol. 2014;121(13):1633-1640. doi: 10.1111/1471-0528.12891.

14. Conde-Agudelo A, Rosas-Bermudez A, Castano F, Norton MH. Effects of birth spacing on maternal, perinatal, infant, and child health: a systematic review of causal mechanisms. Stud Fam Plann. 2012;43:93-114. doi: 10.1111/j.17284465.2012.00308.x.

15. Grisaru-Granovsky S, Gordon ES, Haklai Z, Arnon S, Schimmel M.M. Effect of interpregnancy interval on adverse perinatal outcomes - a national study. Contraception. 2009;80:512-518. doi: 10.1016/j.contraception.2009.06.006.

16. Masinter LM, Dina B, Kjerulff K, Feinglass J. Short interpregnancy intervals: results from the first baby study. Womens Health Issues. 2017,27(4):426-433. doi: 10.1016/j. whi.2017.02.011

17. Ahrens KA, Nelson H, Stidd RL, Moskosky S, Hutcheon JA. Short interpregnancy intervals and adverse perinatal outcomes in high-resource settings: An updated systematic review. Paediatr Perinat Epidemiol. 2019;33(1):O25-O47. doi: $10.1111 /$ ppe. 12503.

18. Mahande MJ, Obure J. Effect of interpregnancy interval on adverse pregnancy outcomes in northern Tanzania: a registry-based retrospective cohort study. BMC Pregnancy Childbirth. 2016;16(1):140. doi: 10.1186/s12884-016-0929-5.

19. Coo H, Brownell MD, Ruth C, Flavin M, Au W, Day AG. Interpregnancy Interval and Adverse Perinatal Outcomes: A Record-Linkage Study Using the Manitoba Population Research Data Repository. J Obstet Gynaecol Can. 2017;39(6):420-433. doi: 10.1016/j.jogc.2017.01.010.

20. Sadia I, Farzana L, Naila Y. Association of short inter-pregnancy interval with adverse perinatal outcome. Pak Postgrad Med J. 2015;26(1):11-17.

21. Stanton C, Lawn JE, Rahman H, Ketende KW, Hill K. Stillbirth rates: delivering estimates in 190 countries. Lancet. 2006;367:1487-1494. doi: 10.1016/S0140-6736(06)68586-3

22. Lawn JE, Yakoob MY, Haws RA, Soomro T, Darmstadt GL, Bhutta ZA. 3.2 million stillbirths: epidemiology and overview of the evidence review. BMC Pregnancy Childbirth. 2009;9(Suppl 1):S2,1-17. doi: 10.1186/1471-2393-9-S1-S2.

23. Hacettepe University Institute of Population Studies, “2013 Turkey Demographic and Health Survey". Hacettepe University Institute of Population Studies, T.R. Ministry of Development and TUBITAK, Ankara, Turkey. 2014; pp:68-69.

24. Zhu BP, Le T. Effect of interpregnancy interval on infant low birth weight: a retrospective cohort study using the Michigan maternally linked birth database. Matern Child Health J. 2003;7:169-178. doi: 10.1023/A:1025184304391.

25. Mahfouz EM, El-Sherbiny NA, Wahed WY, Hamed NS Effect of inter-pregnancy interval on pregnancy outcome: a prospective study at Fayoum, Egypt. Int J Med Dev Ctries. 2018;2(2):38-44. doi: 10.24911/IJMDC.51-1520268317

26. Jafari F, Eftekhar H, Pourreza A, Mousavi J. Socioeconomic and medical determinants of low birth weight in Iran: 20 years after establishment of a primary healthcare network. Public Health. 2010;124(3):153-158. doi: 10.1016/j.puhe.2010.02.003.

27. Seçkin RC, Utku M, Bingol S. Growth status and affecting some sociodemographic factors in infancy. Sted. 2008;17:78,111-117. 